\title{
West Nile virus infection in the intensive care unit: A case series and literature review
}

\author{
Eddy Fan $M D^{1}$, Dale $M$ Needham MAcc CA MD ${ }^{1,2}$, James Brunton $M D^{1,3,6}$, \\ Ralph Z Kern MD ${ }^{1,4,6}$, Thomas E Stewart $\mathrm{MD}^{1,2,5,6}$
}

\begin{abstract}
E Fan, DM Needham, J Brunton, RZ Kern, TE Stewart. West Nile virus infection in the intensive care unit: A case series and literature review. Can Respir J 2004;11(5):354-358.
\end{abstract}

BACKGROUND: West Nile virus (WNV) is a rapidly spreading infectious disease in North America. Critical care issues related to WNV are not well described.

OBJECTIVES: Three cases of severe WNV meningoencephalitis with flaccid paralysis are reported and relevant critical care issues are highlighted.

METHODS: Case series and a review of the literature.

RESULTS: Three patients with WNV meningoencephalitis and flaccid paralysis were admitted to the authors' academic, tertiary-care intensive care unit (ICU) in the late summer of 2002. All three patients were middle-aged or elderly and presented with a febrile illness that preceded or coincided with their neurological symptoms. Confirmation of WNV infection was problematic because each patient had at least one initial negative serum serology test. Radiological testing yielded nonspecific results. Serial electroencephalograms were consistent with severe toxic metabolic encephalopathy in all cases. All patients had a severe, diffuse axonal polyneuropathy demonstrated by nerve conduction studies and electromyography. Prolonged mechanical ventilation resulted in ICU lengths of stay of 44 to 118 days. At one point, $21 \%$ of the ICU beds were dedicated for these patients. All three patients died in hospital - two following the withdrawal of life support. One patient demonstrated resolving encephalitis and was discharged from the ICU after a 118-day ICU stay, but later died in a step-down unit.

CONCLUSIONS: The management of WNV-related critical illness creates challenges in making a timely and accurate diagnosis, and predicting patient morbidity and mortality. As a consequence, endof-life discussions with families are especially difficult. The prolonged ICU length of stay and growing incidence of this disease may challenge limited critical care resources.

Key Words: Case report; Critical care; Encephalitis; Intensive care units; Paralysis; West Nile virus

W est Nile virus (WNV) is a newly established infectious disease in North America that can cause critical illness. Since its introduction in 1999, this mosquito-borne flavivirus has rapidly spread to 44 states in the United States, as well as southern Ontario, Quebec and western Canada (1-3). Epidemics of WNV with severe neurological disease leading to critical illness have been reported previously (4). North American intensivists need to be aware of the new challenges of WNV.

\section{Infection par le virus du Nil occidental à l'unité des soins intensifs : Série de cas et revue de la littérature}

HISTORIQUE : Le virus du Nil occidental (VNO) provoque une infection dont l'incidence augmente rapidement en Amérique du Nord. Les soins critiques requis pour venir à bout de cette infection n'ont pas encore été bien décrits.

OBJECTIFS : Trois cas de méningo-encéphalite à VNO sévères avec paralysie flasque sont signalés et on présente les principaux enjeux relatifs aux soins critiques.

MÉTHODE : Série de cas et revue de la littérature.

RÉSULTATS : Trois patients atteints de méningo-encéphalite à VNO avec paralysie flasque ont été admis à l'unité des soins intensifs de l'établissement des auteurs à la fin de l'été 2002. Les trois patients étaient d'âge moyen ou avancé et présentaient une fièvre ayant précédé ou coïncidé avec leurs symptômes neurologiques. La confirmation de l'infection à VNO s'est révélée problématique parce que chaque patient a présenté au moins un test sérologique initial négatif. Les épreuves radiologiques ont donné des résultats non spécifiques. Les électroencéphalogrammes en série concordaient avec une encéphalopathie métabolique toxique sévère dans tous les cas. Tous les patients présentaient une polyneuropathie axonale diffuse sévère confirmée par des tests de conduction nerveuse et d'électromyographie. La ventilation mécanique prolongée a occasionné des séjours de 44 à 118 jours à l'unité des soins intensifs. À un moment, $21 \%$ des lits de soins intensifs étaient consacrés à ces patients. Les trois patients sont décédés à l'hôpital, deux d'entre eux après l'arrêt du respirateur, tandis que l'autre a présenté une amélioration de son encéphalite et a reçu son congé de l'unité après un séjour de 118 jours. Il est plus tard décédé dans un autre département de l'hôpital.

CONCLUSION : La maladie à VNO critique et sa prise en charge posent des défis; il est notamment difficile d'établir rapidement un diagnostic précis et d'en prévoir la morbidité et de la mortalité. C'est entre autres pourquoi la discussion sur les conditions de fin de vie avec les proches des malades est particulièrement délicate. Le séjour prolongé à l'unité des soins intensifs et l'incidence croissante de cette maladie pourraient en outre menacer gravement les maigres ressources consacrées aux soins critiques.

In the present paper, three patients with WNV infection leading to critical illness admitted to the Mount Sinai Hospital intensive care unit (ICU) (Toronto, Ontario) in late summer of 2002 are described. The present cases represent a subset of a recently published case series (5). The patients' clinical presentation, radiological and neurological investigations (Table 1), cerebral spinal fluid (CSF) analysis (Table 2) and WNV serology results (Table 3) are summarized, along with a review of the literature focusing on critical care issues. The

${ }^{1}$ Department of Medicine, ${ }^{2}$ Interdepartmental Division of Critical Care, ${ }^{3}$ Division of Infectious Diseases, ${ }^{4}$ Division of Neurology and ${ }^{5}$ Department of Anesthesia, University of Toronto, Toronto; ${ }^{6}$ Mount Sinai Hospital and University Health Network, Toronto, Ontario

Correspondence: Dr Thomas E Stewart, Critical Care Units, Mount Sinai Hospital and University Health Network, 600 University Avenue,

Suite 1818, Toronto, Ontario M5G 1X5. Telephone 416-586-8774, fax 416-586-5981, e-mail tom.stewart@utoronto.ca 
TABLE 1

Summary of radiological and neurological investigations

\begin{tabular}{|c|c|c|c|c|}
\hline Patient & Computed tomography & MRI & EMG/NCS & EEG \\
\hline 1 & $\begin{array}{l}\text { Day } 4 \text { - Normal } \\
\text { Day } 8 \text { - Normal }\end{array}$ & $\begin{array}{l}\text { Day } 13 \text { - Normal } \\
\text { Day } 23-\text { Normal }\end{array}$ & $\begin{array}{l}\text { Day } 15 \text { - Diffuse axonal } \\
\text { polyneuropathy } \\
\text { Day } 40 \text { - No change }\end{array}$ & $\begin{array}{l}\text { Day } 15 \text { - Severe, toxic metabolic } \\
\text { encephalopathy } \\
\text { Day } 36 \text { - No change } \\
\text { Day } 41 \text { - No change }\end{array}$ \\
\hline 2 & $\begin{array}{l}\text { Day } 2 \text { - Normal } \\
\text { Day } 4 \text { - Normal } \\
\text { Day } 6 \text { - Normal } \\
\text { Day } 23 \text { - Vague hypoattenuations } \\
\text { within right subinsular tissues } \\
\text { anteriorly, left subthalamus and } \\
\text { posterior left pons due to } \\
\text { leptomeningeal disease or ischemia }\end{array}$ & $\begin{array}{l}\text { Day } 6 \text { - Areas of signal } \\
\text { abnormality involving brainstem, } \\
\text { cerebellum and right thalamus, } \\
\text { possibly consistent with } \\
\text { leptomeningeal process } \\
\text { Day } 59 \text { - No significant change }\end{array}$ & $\begin{array}{r}\text { Day } 39 \text { - Severe, diffuse } \\
\text { axonal polyneuropathy }\end{array}$ & $\begin{array}{l}\text { Day } 6 \text { - Severe, toxic } \\
\text { metabolic encephalopathy } \\
\text { Day } 11 \text { - No change } \\
\text { Day } 17 \text { - No change } \\
\text { Day } 54 \text { - No change } \\
\text { Day } 67 \text { - Marginal improvement } \\
\text { in background activity }\end{array}$ \\
\hline 3 & Day 4 - Normal & $\begin{array}{l}\text { Day } 10 \text { - Microangiopathic } \\
\text { white matter disease } \\
\text { Day } 82 \text { - No change }\end{array}$ & $\begin{array}{l}\text { Day } 33 \text { - Severe, diffuse } \\
\text { axonal polyneuropathy } \\
\text { Day } 79 \text { - No change }\end{array}$ & $\begin{array}{l}\text { Day } 25 \text { - Severe, toxic } \\
\text { metabolic encephalopathy }\end{array}$ \\
\hline
\end{tabular}

EEG Electroencephalogram; EMG/NCS Electromyography and nerve conduction studies; MRI Magnetic resonance imaging

TABLE 2

Cerebrospinal fluid (CSF) analysis

\begin{tabular}{|c|c|c|c|c|c|c|}
\hline Patient & $\begin{array}{c}\text { Days after } \\
\text { symptom onset }\end{array}$ & $\begin{array}{c}\text { WBC } \\
\left(1 \times 10^{9} / L\right)\end{array}$ & $\begin{array}{c}\text { PMN } \\
(\%)\end{array}$ & $\begin{array}{c}\text { RBC } \\
\left(1 \times 10^{12} / L\right)\end{array}$ & $\begin{array}{l}\text { Protein }^{*} \\
\text { (g/L) }\end{array}$ & $\begin{array}{l}\text { Glucose }^{\dagger} \\
(\mathrm{mmol} / \mathrm{L})\end{array}$ \\
\hline \multirow[t]{2}{*}{1} & Day 4 & 0.171 & 65 & 0.7500 & 0.83 & $4.5(8.6)$ \\
\hline & Day 10 & 0.001 & 0 & 0.8200 & 0.97 & $4.5(10.5)$ \\
\hline \multirow[t]{3}{*}{2} & Day 5 & 0.016 & 29 & 0.0670 & 0.56 & $3.2(6.2)$ \\
\hline & Day 26 & 0.006 & 0 & 0.0002 & & \\
\hline & Day 45 & 0.009 & 0 & 0.0026 & 0.54 & $3.6(7.9)$ \\
\hline 3 & Day 14 & 0.004 & 0 & 0.0002 & & \\
\hline
\end{tabular}

*Normal range for CSF protein is $0 \mathrm{~g} / \mathrm{L}$ to $0.45 \mathrm{~g} / \mathrm{L}$; ${ }^{+}$Normal range for CSF glucose is less than two-thirds the corresponding serum glucose (presented in parentheses). WBC White blood cells; PMN Polymorphonuclear leukocyte; RBC Red blood cells

timeline of patients' clinical events are presented as days from symptom onset. Consent was obtained for inclusion of the patients' clinical information in the present case series.

\section{CASE PRESENTATIONS}

Case 1

A 78-year-old man presented to the emergency room with chest pain and fever. On physical examination, no specific abnormalities were noted in the cardiac, respiratory or neurological systems. Serial electrocardiograms and cardiac enzymes were negative for acute cardiac ischemia. The patient was treated empirically for community-acquired pneumonia. Three days later (day 3), his level of consciousness deteriorated, requiring endotracheal intubation and transfer to the ICU. A brain computed tomography (CT) scan and lumbar puncture (LP) were consistent with possible infection (Tables 1 and 2). The antibiotic regimen was modified to cover bacterial meningitis. By day 12, flaccid paralysis developed. Brain magnetic resonance imaging (MRI) confirmed the absence of structural abnormalities, and electromyography and nerve conduction studies (EMG/NCS) revealed a severe diffuse axonal polyneuropathy. Treatment with intravenous immunoglobulin (IVIG)
TABLE 3

Timeline of West Nile virus serology results

\begin{tabular}{lll}
\hline Patient & Negative serology $^{*}$ & Positive serology $^{\dagger}$ \\
\hline 1 & Day 6 & Day $19(\geq 1: 320)$ \\
2 & Days 5,13 and 16 & Day $41(\geq 1: 320)$ \\
& & Day 54 (serum and CSF \\
3 & Day 11 & $\geq 1: 320)$ \\
\hline
\end{tabular}

Results are for hemagglutination inhibition titres on serum unless otherwise indicated. *Negative West Nile virus serology represents a titre of less than one-tenth by hemagglutination inhibition; + Specificity confirmed by plaque reduction neutralization test (in parentheses)

resulted in no improvement. Repeated electroencephalograms (EEG) were consistent with a severe, toxic metabolic encephalopathy (Table 1). The initial serum WNV serology on day 6 was negative, but was positive with repeat testing on day 19 (Table 3).

After a prolonged ICU course and no clinical improvements, in consultation with the family, further aggressive medical therapy was withheld and the patient died on day 47 . Postmortem examination of the brain revealed diffuse Lewy body disease, cerebellar degeneration and subacute encephalitis with a predilection for the diencephalon and brainstem (primarily, the medulla) with features of multifocal necrotizing leukoencephalopathy. The mononuclear infiltrate present in the brainstem took the form of glial and microglial nodules. These findings were consistent with an arboviral infection such as WNV.

Case 2

A 57-year-old woman presented to a community hospital with a three-day history of fever, malaise and right arm weakness. She had been discharged from a hospitalization for an autologous stem cell transplant for treatment of non-Hodgkin's lymphoma 
nine days before. Post-transplant, she was supported with blood products, as required. Upon admission, she was pancytopenic, but not neutropenic, and had a brief generalized seizure. A brain CT was unremarkable. She received broad-spectrum antibiotics and phenytoin. Subsequently, she acutely developed aphasia, bilateral rightward deviation of her eyes, nuchal rigidity and left arm weakness which progressed to generalized weakness within two days of admission. Her antibiotics were broadened to include antiviral and antifungal therapy, and she was transferred to the Mount Sinai Hospital ICU.

In the ICU, the patient was intubated. A repeat brain CT scan revealed no significant abnormalities. Repeated LPs with CSF analysis (Table 2) had negative culture and cytology results. On day 6 , a gadolinium-enhanced brain MRI revealed possible leptomeningeal disease and an EEG was consistent with a severe, toxic metabolic encephalopathy (Table 1). Despite previously negative CSF viral studies and a lack of clinical correlation, a repeat LP on day 26 was positive for herpes simplex virus by polymerase chain reaction. A three-week course of intravenous acyclovir was instituted. On day 39, EMG/NCS revealed a severe diffuse axonal polyneuropathy. A five-day course of IVIG resulted in no improvement. WNV serology from days 5, 13 and 16 were negative. Repeat WNV serology on day 41 was positive and reconfirmed on day 54 (Table 3 ). After no signs of improvement, on day 69, in discussion with the family, life support was withdrawn and the patient expired. Subsequent investigation revealed that the patient's WNV infection was transfusion-acquired.

\section{Case 3}

An 83-year-old man was admitted to hospital with a two-day history of altered level of consciousness and fever. On physical examination, the patient was unable to obey commands and had incoherent speech. Brain CT revealed no significant abnormalities and LP was unsuccessful. The patient was empirically treated for bacterial and viral meningitis with antibiotics and acyclovir. On day 6, he became progressively more obtunded, and he was intubated and transferred to the ICU. Physical examination revealed intact brainstem reflexes and flaccid paralysis. A gadolinium-enhanced brain MRI on day 10 revealed no significant abnormality. A fluoroscopic-guided LP on day 14 revealed no CSF evidence of meningitis. Serum WNV serology was negative on day 11 , but was positive with repeat testing on day 17 (Table 3). EEG on day 25 was compatible with a severe, diffuse, toxic metabolic encephalopathy and EMG/NCS was compatible with a severe diffuse axonal polyneuropathy.

Clinical evidence of resolving encephalitis was first recognized on day 65. An increased level of consciousness and appropriate attempts at communication continued thereafter with gradual, but fluctuating, improvement. Slow improvement in motor strength was noted in the left and then the right arm, with virtually no motor strength in the legs. Repeat EMG/NCS and MRI on days 79 and 82, respectively, were unchanged. Early attempts at weaning were unsuccessful, but after 108 days of mechanical ventilation the patient was liberated. After 118 days in the ICU, the patient was transferred to a step-down unit. On day 122, he had an asystolic cardiac arrest and expired.

\section{Epidemiology}

\section{DISCUSSION}

WNV is a flavivirus endemic to Africa, the Middle East, southwestern Asia and Eastern Europe. In these regions, WNV infection usually results in asymptomatic illness. With its recent introduction in the United States, the reported cases of WNV infection have rapidly increased from 149 in 1999 to 2001 to over 3300 in 2002 (1). Since its initial introduction into Canada, in southwestern Ontario and Quebec, cases of WNV infection have spread to include Manitoba, Saskatchewan, Alberta and Nova Scotia (3).

\section{Symptoms}

The incubation period of WNV is three to 14 days with clinically overt disease occurring in approximately $20 \%$ of individuals $(2,4,6,7)$. Common symptoms include fever, malaise, anorexia, nausea, vomiting, eye pain, headache, myalgia, rash and lymphadenopathy (4). Only 32\% of patients recall a mosquito bite in the month preceding symptom onset (8). Common neurological manifestations include aseptic meningitis, encephalitis and neuromuscular paralysis with prominent motor axon or anterior horn cell dysfunction on EMG/NCS. Other, less common, neurological presentations include seizures, extrapyramidal signs, optic neuritis, other cranial nerve abnormalities, myelitis and polyradiculitis (7).

\section{Critical illness}

In recent experience, WNV-related critical illness most often results from meningoencephalitis and flaccid paralysis. Among the reported cases of symptomatic WNV infection in the United States in 2002, 69\% developed meningoencephalitis (1). The most significant risk factor for severe neurological disease following WNV infection is being over 50 years of age, with much higher risk in those over 80 years of age $(8,9)$. The involvement of spinal cord gray matter, specifically the anterior horn cells, has been implicated in the pathogenesis of WNV-related acute flaccid paralysis, resulting in a poliomyelitis-type illness (10-12). While the acute presentation of a polio-like condition, such as in WNV infection, may initially simulate Guillain-Barre syndrome (GBS), a careful review of the clinical features and electrodiagnostic studies will reveal findings that are atypical for GBS. The presence of fever, rash, and abdominal and back pain before the onset of flaccid paralysis are useful clinical features in distinguishing WNV infection from GBS (13).

\section{Diagnosis}

The diagnosis of WNV infection relies on a high index of suspicion coupled with appropriately timed serological testing. Infection with WNV or other arboviruses should be considered in adults presenting with unexplained fever and neurological symptoms who live in, or have travelled to, appropriate geographic regions. In the northeastern United States and southern Ontario and Quebec, infection can occur in late summer or early fall. In the southern United States, WNV can be transmitted from June to November (1). While the majority of human WNV infection occurs from mosquito bites, several other modes of transmission have been recognized, including transplacental, transfusion of blood products and solid organ 
transplantation (2). The most common and preferred diagnostic test is the immunoglobulin M (IgM) antibody-capture enzymelinked immunosorbant assay (ELISA), which can be performed on serum or CSF. The presence of the antibody in CSF is highly suggestive of a neurological infection (14). Individuals recently vaccinated for, or infected with, other related flaviviruses may have a positive WNV IgM ELISA (2). In hospitalized patients, IgM antibodies to WNV have been isolated within eight days of symptom onset in 95\% of CSF specimens and 90\% of serum specimens (15). Because this assay may not be positive at initial patient presentation, as demonstrated in the present case series, serological testing should be repeated when there is a high clinical suspicion for WNV infection.

The earliest positive serology obtained in the present three patients was 17 days after symptom onset (case 2). This time lag may, in part, relate to slow turnaround times from provincial health laboratories for the hemagglutination inhibitory tests (HAI) used to diagnose WNV in the present patients. During the summer of 2002, the HAI test was the only serological test available in provincial health laboratories. In immunosuppressed patients, such as case 2, a slow antibody response may further delay positive diagnostic results for both HAI and ELISA assays. Both nucleic acid amplification and antigen detection may be needed to ensure early detection of WNV infection in immunocompromised individuals. The plaque-reduction neutralization test can help confirm results established by rapid WNV detection assays and can also distinguish serological cross-reactions among the flaviviruses (2).

\section{Treatment}

Currently, the treatment for WNV infection is supportive. In New York City, $26 \%$ to $32 \%$ of hospitalized patients were admitted to the ICU and $11 \%$ to $17 \%$ required mechanical ventilation $(8,16)$. A case report (17) from Israel suggested neurological improvement in a comatose patient with confirmed WNV infection who was treated with locally collected IVIG. While there are no controlled human trials of IVIG in WNV infection, the efficacy of pooled IVIG had been demonstrated in a murine model (18). There is currently no evidence to support the use of ribavirin, interferon-alpha2b, steroids, anticonvulsants or plasmapheresis (4). Clinical trials are necessary to determine whether these therapies will be effective in reducing the neurological complications of WNV infection.

\section{Prognosis}

Case fatality rates among hospitalized patients are $4 \%$ to $14 \%(8,19,20)$. In 2002 , the mortality rate for WNV meningoencephalitis in the United States was 9\% (1). Advanced age and diabetes were the most significant risk factors for death (8). Encephalitis with profound muscle weakness was also prognostically important (8). Mortality may be much higher among patients admitted to the ICU, especially those requiring mechanical ventilation (14). Important morbidity may follow severe WNV infection, including residual weakness and short-term memory loss $(14,16)$. In a case series of 57 hospitalized WNV patients from Ontario in 2002 (5), 80\% of discharged patients had impairment in their functional status from persistent ataxia, weakness and cognitive dysfunction (5). Recovery can be further delayed in immunocompromised individuals
(14) and ICU survivors due to both the primary infection and complications related to prolonged hospital admission.

\section{Other critical care issues}

Our WNV experience highlights two additional important issues for intensivists. Due to limited experience with severe WNV infection in North America, its natural history and potential long-term morbidity are poorly understood. This uncertainty is compounded by the time delay in obtaining serological diagnosis of WNV infection and the lack of definitive treatment. These factors make discussions with families regarding the use or continuation of life support especially challenging. To our knowledge, the patient in case 3 had the longest duration of mechanical ventilation with survival to ICU discharge. His clinical course provided insight into the natural history of possible resolution of WNV encephalitis and recovery of respiratory muscle strength to allow liberation from mechanical ventilation. However, more data are required to better understand the outcomes of critically ill patients infected with WNV.

Second, WNV may have a significant impact on limited critical care resources. In the past three years, there has been a greater than 20-fold increase in reported cases of WNV infection. Transmission of WNV via blood products and solid organ transplantation $(2,21)$ further increases the possibility of infection. During previous WNV outbreaks, up to one-third of hospitalized patients required ICU admission, with approximately $50 \%$ requiring mechanical ventilation $(1,19)$. Our experience has demonstrated that patients with severe neurological disease require prolonged mechanical ventilation, but may have the potential for improvement. Even in cases where life support is withdrawn, the uncertainty surrounding WNV prognosis delays these decisions. As a consequence, the present ICU length of stay for these patients ranged from 47 to 118 days. Within the Mount Sinai Hospital ICU, three of 14 (21\%) beds were devoted to these patients. In addition to the use of limited ICU resources, the delay in serological confirmation of WNV infection leads to many costly investigations and treatments for other possible diagnoses.

\section{CONCLUSIONS}

As WNV infection rapidly increases in North America, the potential for critical illness due to meningoencephalitis and flaccid paralysis is a growing concern, especially in the elderly and immunocompromised. Patients with WNV have an uncertain clinical course with significant morbidity and mortality. For intensivists, these patients can represent a significant challenge for diagnosis, treatment and end-of-life decision-making. Furthermore, prolonged critical illness of severe WNV infection may challenge limited ICU resources. These issues will become increasingly important because the number of cases of severe WNV infection is expected to rise. Rapid diagnostic tests, clinical trials of vaccines and specific therapies, and additional data on the natural history of this infection are required for more effective management of WNV infection.

ACKNOWLEDGEMENTS: We thank Drs Rob Dumais, Elana Maser and Colleen McDermott for their assistance with compilation of the clinical and laboratory data presented in the case summaries. 


\section{REFERENCES}

1. Chow CC, Montgomery SP, O'Leary DR, et al. Provisional surveillance summary of the West Nile virus epidemic United States, January-November 2002. Morb Mortal Wkly Rep 2002;51:1129-33.

2. Petersen LR, Marfin AA, Gubler DJ. West Nile virus. JAMA 2003;290:524-8.

3. West Nile virus: Canada. Human surveillance: Results of 2003 program. Human test results by province. Ottawa: Population and Public Health Branch, Health Canada, 2003. $<$ www.hc-sc.gc.ca/pphb-dgspsp/wnv-vwn/monarch03 _e.html\#human03>

4. Petersen LR, Marfin AA. West Nile virus: A primer for the clinician. Ann Intern Med 2002;137:173-9.

5. Pepperell C, Rau N, Krajden S, et al. West Nile virus infection in 2002: Morbidity and mortality among patients admitted to hospital in southcentral Ontario. CMAJ 2003;168:1399-405.

6. Mostashari F, Bunning ML, Kitsutani PT, et al. Epidemic West Nile encephalitis, New York 1999: Results of a household-based seroepidemiological survey. Lancet 2001;358:261-4.

7. Campbell GL, Marfin AA, Lanciotti RS, Gubler DJ. West Nile virus. Lancet Infect Dis 2002;2:519-29.

8. Nash D, Mostashari F, Fine A, et al, for the 1999 West Nile Outbreak Response Working Group. The outbreak of West Nile virus infection in the New York City area in 1999. N Engl J Med 2001;344:1807-14.

9. Serosurveys for West Nile virus infection - New York and Connecticut counties, 2000. Morb Mortal Wkly Rep 2001;50:37-9.

10. Sejvar JJ, Leis AA, Stokic DS, et al. Acute flaccid paralysis and West Nile virus infection. Emerg Infect Dis 2003;9:788-93.
11. Leis AA, Stokic DS, Polk JL, Dostrow V, Winkelmann M. A poliomyelitis-like syndrome from West Nile virus infection. N Engl J Med 2002;347:1279-80.

12. Glass JD, Samuels O, Rich MM. Poliomyelitis due to West Nile virus. N Engl J Med 2002;347:1280-1.

13. Jeha LE, Sila CA, Lederman RJ, Prayson RA, Isada CM, Gordon SM. West Nile virus infection: A new acute paralytic illness. Neurology 2003;61:55-9.

14. Asnis DS, Conetta R, Teixeira AA, Waldman G, Sampson BA. The West Nile Virus outbreak of 1999 in New York: The Flushing Hospital experience. Clin Infect Dis 2000;30:413-8.

15. West Nile Virus Surveillance and Control: An Update for Healthcare Providers in New York City. New York: New York Department of Health, City Health Information, 2001:20.

16. Weiss D, Carr D, Kellachan J, et al. Clinical findings of West Nile virus infection in hospitalized patients, New York and New Jersey, 2000. Emerg Infect Dis 2001;7:654-8.

17. Shimoni Z, Niven MJ, Pitlick S, Bulvik S. Treatment of West Nile virus encephalitis with intravenous immunoglobulin. Emerg Infect Dis 2001;7:759.

18. Ben-Nathan D, Lustig S, Tam G, Robinzon S, Segal S, Rager-Zisman B. Prophylactic and therapeutic efficacy of human intravenous immunoglobulin in treating West Nile virus infection in mice. J Infect Dis 2003;188:5-12.

19. Chowers MY, Lang R, Nassar F, et al. Clinical characteristics of the West Nile fever outbreak, Israel, 2000. Emerg Infect Dis 2001;7:675-8.

20. Tsai TF, Popovici F, Cernescu C, Campbell GL, Nedelcu NI. West Nile encephalitis epidemic in southeastern Romania. Lancet 1998;352:767-71.

21. Investigations of West Nile virus infection in recipients of blood transfusions. Morb Mortal Wkly Rep 2002;51:973-4. 


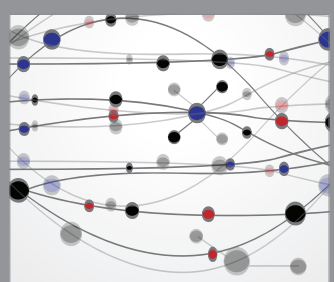

The Scientific World Journal
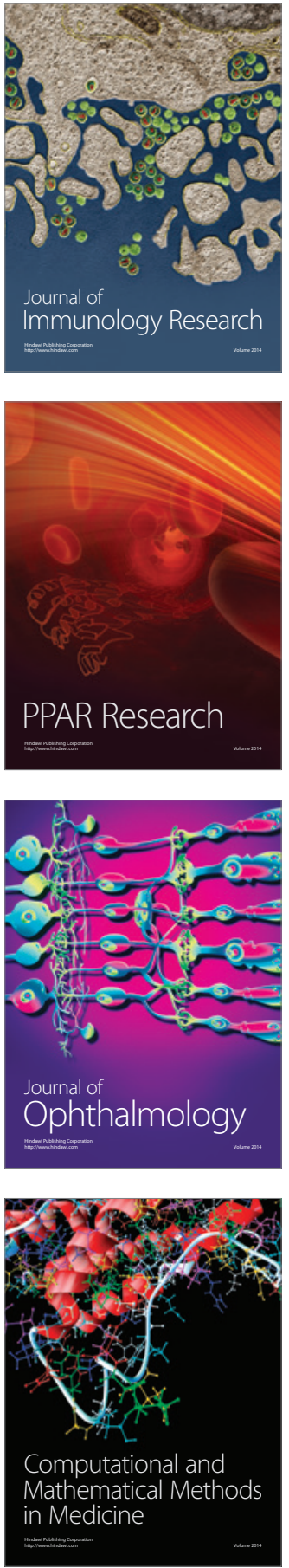

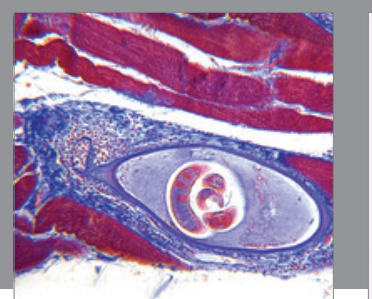

Gastroenterology Research and Practice

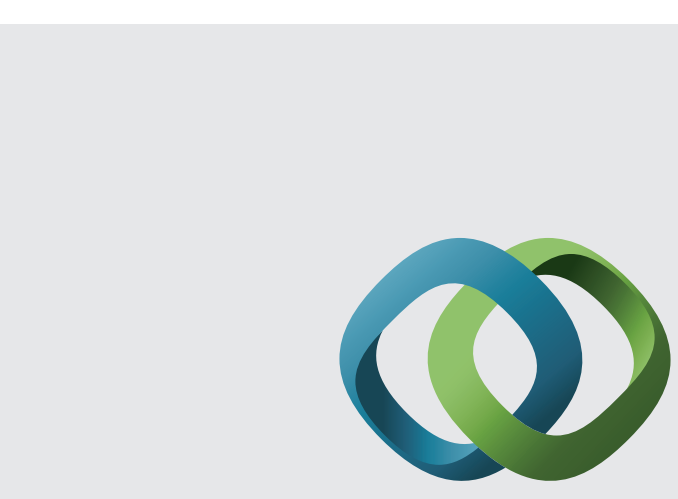

\section{Hindawi}

Submit your manuscripts at

http://www.hindawi.com
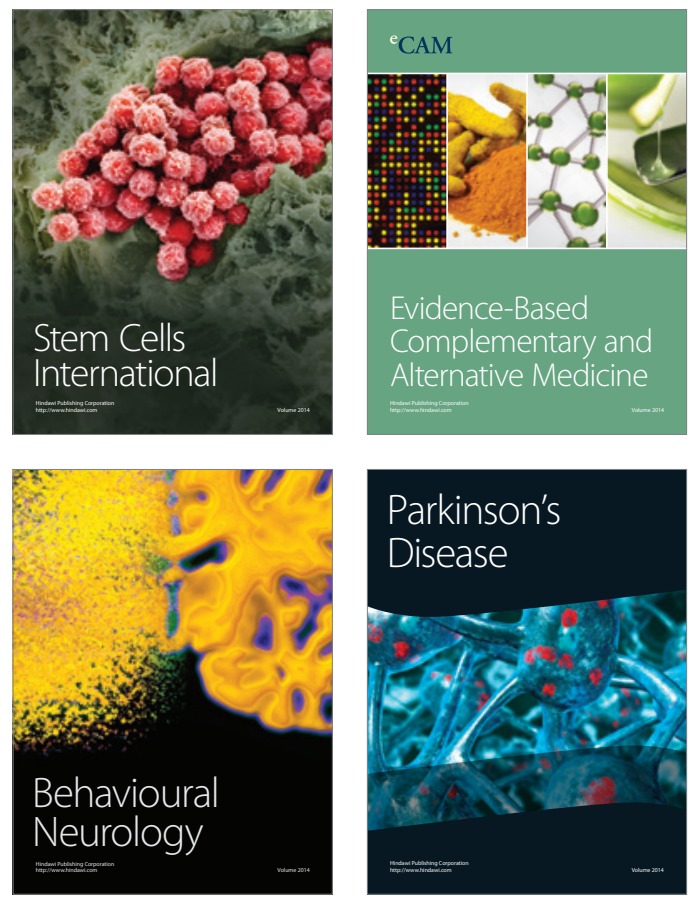
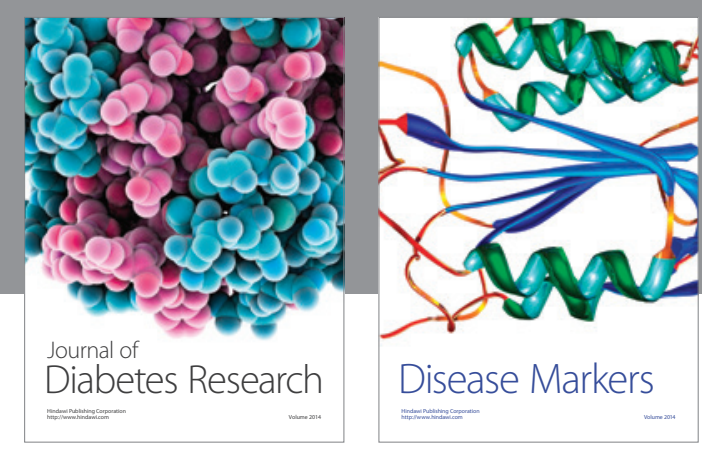

Disease Markers
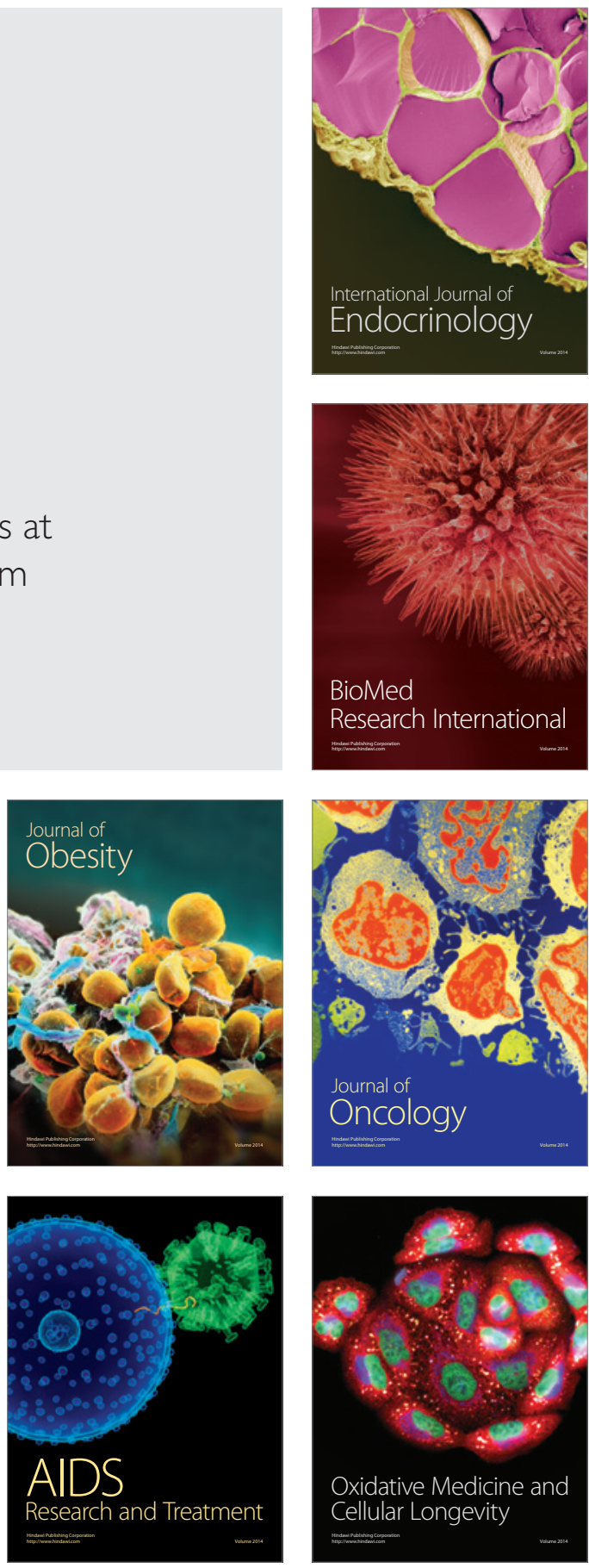